${ }^{13}$ Williams BM, Richards DW, Lewis J. Salmonella infection in the herring-gull (Lans argentatus). Vet Rec 1976;98:51.

14 Trawinski A, Trawinska J. Studies on the transmission of salmonellae by the developmental stages of flies. Annales Universitatis Mariae CurieSkłodowska 1960;13, sect D D:31-40.

15 Williams BM. Environmental consideration in salmonellosis. Vet Rec $1975 ; 96: 318-21$.

${ }^{16}$ Lawson GHK, McPherson EA, Laing AH, Wooding P. The epidemiology of Salmonella dublin infection in a dairy herd. $\mathcal{F}$ Hyg $1974 ; 72: 311-28$.

17 Williams E. Salmonella dublin skin lesions in a veterinary surgeon. Lancet 1969;ii:737-9.

18 Haxthausen $\mathrm{H}$, Thomsen A. Brucella eruption in veterinary surgeons Archives of Dermatology and Syphilology $1931 ; 163: 477-91$.

19 Huddleson IF. Brucellosis in man and animals. New York: Commonwealth Fund, 1943.

${ }^{20}$ Spink WW. The nature of brucellosis. Minneapolis: University of Minnesota Press, 1956.

${ }^{21}$ Christie AB. Infectious diseases: epidemiology and clinical practice. Edinburgh and London: Churchill Livingstone, 1974

22 Williams E. Brucellosis in veterinary surgeons in Wales. $\mathcal{F}$ Coll Physicians Lond 1976;10:351-62.

${ }^{23}$ Fujimura S, Hoshi T. A case of human infection with Salmonella abortus equi. Fournal of the Fapanese Society of Veterinary Science 1936;15: 159-63.

${ }^{24}$ Pantekoek JFCA, Rhodes CS, Saunders JR. Salmonella folliculitis in veterinarians infected during obstetrical manipulation of a cow. Can Vet $\mathcal{F} 1974 ; 15: 123-5$.

25 Dijkstra RG. Infection of the skin by Listeria monocytogenes. Tijdschr Diergeneeskd 1959;84:719.

${ }^{26}$ Mouton RP, Kampelmacher EH. Listeria infection of the human skin. In: Proceedings of the third international symposium on listeriosis. Utrecht: Bilthoven, 1966:425-31.

27 Kalkoff KW, Schiff W. Listeriosis of the skin from contact infection. Hautarzt 1960;11:201-4.

${ }^{8}$ Owen CR, Meis A, Jackson JW, Stoenner HG. A case of primary cutaneous listeriosis. N Engl f Med 1960;262:1026-8.

${ }^{29}$ Editorial. Very important observations on the aetiology of epidemic puerperal fever in maternity hospitals. Zeitschrift der kaiserlichköniglichen Gesellschaft der Aerzte zu Wien 1847;4:242-4.

30 Bell P. Brucellosis: do vets risk spread ? British Farmer 1968 Nov 2:28-9.

${ }^{31}$ Morgan WJB. Brucella abortus. In: Blobel H, Schliesser Th, eds. Handbook of bacterial infection in animals. Jena: V E B Gustav Fisher Publishing House. (In press).

${ }^{32}$ Bang B. The aetiology of epizootic abortion. 7 Comp Pathol 1897;10: 125-49.

${ }^{33}$ Osborne AD, Pearson H, Linton AH, Shimeld C. Epidemiology of salmonella infection in calves: the source of calfhood infection by Salmonella dublin. Vet Rec 1977;101:513-6.

(Accepted 18 fanuary 1980)

\title{
A pressure profile for elastic stockings
}

\author{
J HORNER，L C LOWTH，A N NICOLAIDES
}

\section{Summary and conclusions}

Special equipment to measure the circumferential compression exerted by an elastic stocking was used to determine the "pressure-girth profiles" of several types of elastic stocking. Once the pressure-girth profile has been determined, the pressure exerted at the ankle, calf, and thigh can be predicted for any size of limb without further pressure measurements. An excellent correlation $(\mathbf{r}=0.96)$ was obtained when this method was compared with another well-established one of measuring the pressures exerted by stockings.

The method has several potential applications in quality control during stocking manufacture and, clinically, in determining whether a stocking exerts a graduated pressure on a particular limb.

\section{Introduction}

Elastic stockings have been used to treat varicose veins and their complications for over 150 years. ${ }^{1}$ Recent workers have emphasised that elastic stockings need to exert a graduated compression on the leg to encourage the centripetal flow of blood. ${ }^{2}{ }^{3}$ Thromboembolic-deterrent stockings have recently been shown to be effective in reducing the incidence of postoperative deep venous thrombosis. ${ }^{45}$

Methods of measuring the compression of elastic stockings on a limb have been based on the insertion of a pressure sensor, in the form of a fluid- or air-filled balloon, between the stocking and the limb. ${ }^{6-8}$ This balloon is connected to a manometer which records the pressure exerted by the stocking. Stockings may also be factory tested after manufacture for quality control

Academic Surgical Unit, Clinical Vascular Laboratory, St Mary's Hospital Medical School, London, and Scholl Research Laboratory, London

J HORNER, MB, FRCS, senior registrar

L C LOWTH, technical director, Scholl (UK) Ltd

A N NICOLAIDES, MS, FRCS, senior lecturer in cardiovascular surgery, director, clinical vascular laboratory by using "limb forms," usually made of wood, which have builtin electronic pressure sensing devices. A further method determines the circumferential tension of a segment of cloth after it has been cut out as a "window" from the stocking. Details of the last two methods have not been published.

All these techniques, however, have several intrinsic defects. Firstly, the pressure sensors may themselves distort the limb circumference and produce incorrect pressure measurements. Secondly, each patient requires time-consuming individual testing with a particular stocking for an accurate assessment of the stocking's circumferential compression. Thirdly, if the limb circumference changes, retesting and refitting is needed. Fourthly, as the limb dimensions of patients are infinitely variable, an infinite number of limb forms would theoretically be required to assess the corresponding compression for specific combinations of leg lengths and girths. Finally, excision of a square of cloth from a stocking to determine its tension ruins the stocking, is time-consuming, and prevents further testing for quality control.

The compressive effect of a stocking on a limb depends on the elastic tensile strength of the garment and the girth of the limb at different levels. A pressure-girth profile based on the compression at ankle, calf, and thigh will therefore assist the correct prescription of elastic stockings for different limbs.

We describe a new device for pressure grading elastic stockings, which overcomes these problems. It consists of an inflatable, elongated latex balloon which is placed inside the stocking to be tested. Gas under known pressure is then introduced into the balloon. Fig 1 shows the device schematically and shows a stocking in situ ready for testing.

\section{Methods}

Determination of pressure-girth profile-The stocking is placed on the device and stretched over the partially inflated balloon. At its upper end (thigh) the stocking is secured around a movable collar (fig 1). This collar may be positioned so as to give a leg length corresponding to that of a particular limb. Air is then admitted into the balloon under pressure. As the volume of the distended but unstretched balloon exceeds that of the largest size of stocking to be tested, the balloon merely acts as an airseal inside the stocking. Therefore no distortion 


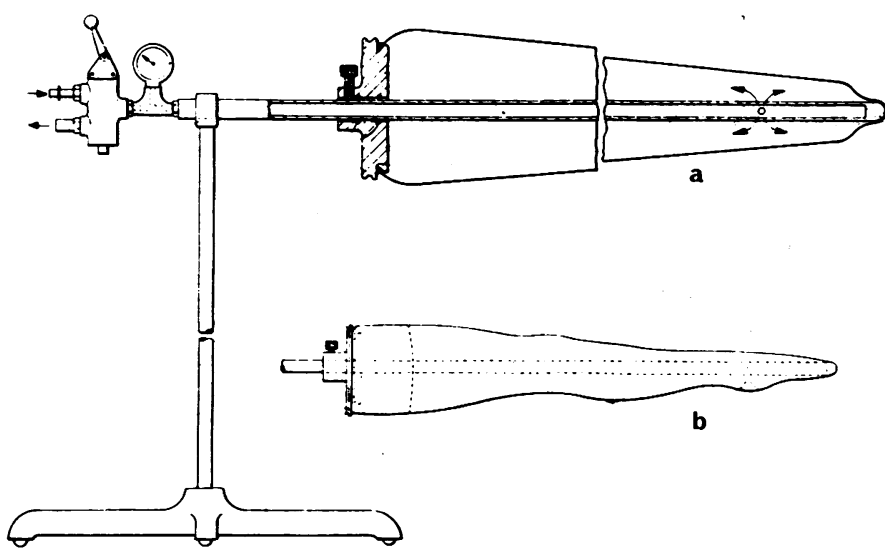

FIG 1 - (a) Diagrammatic representation of device for determining pressure-girth profile and (b) stocking in situ on the device.

of the pressures due to the elasticity of the latex balloon itself occurs. When the stocking has been filled with air, it assumes the shape of a leg of preset length. The stocking is then inflated through a range of girths at the narrowest part above the ankle, at the widest part of the calf, and at the thigh, $15 \mathrm{~cm}$ proximal to the patella. The pressures registered at each girth measurement are read directly from the manometer attached to the devices. In this way a pressure-girth profile is obtained (see figs 2-4).

Comparison with an established technique-The new method was compared with an established technique, ${ }^{7}$ whereby a water-filled polyvinyl bag measuring $4 \times 4 \mathrm{~cm}$ was placed between the stocking and the limb at ankle, calf, and thigh. The fluid-filled bag was connected via nylon tubing measuring $1 \mathrm{~mm}$ in diameter to a pressure transducer and thence to a pen recorder. Calibration was achieved by applying a sphygmomanometer cuff to the limb and placing the fluidfilled bag between the cuff and the limb. The cuff was then inflated through pressures ranging from 0 to $50 \mathrm{~mm} \mathrm{Hg}$. Measurements were

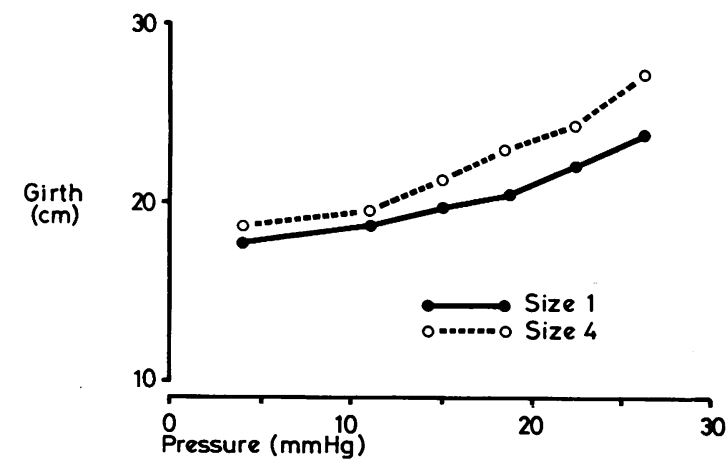

FIG 2-Ankle pressure-girth profile of two stockings (sizes 1 and 4$)$.

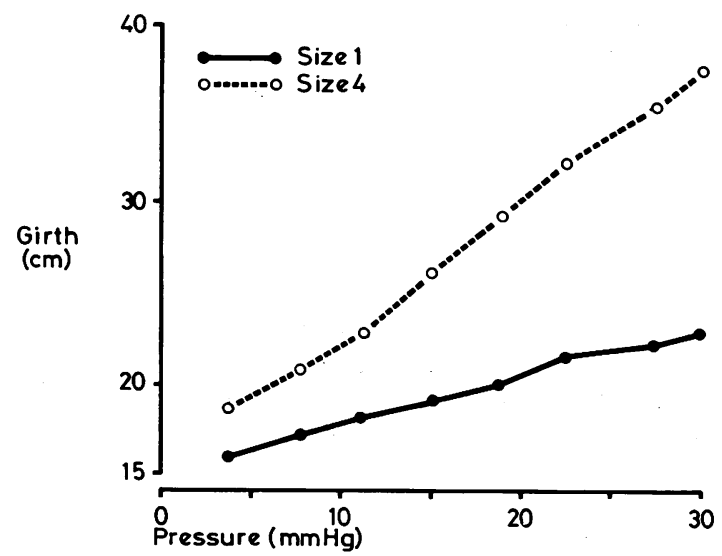

FIG 3-Calf pressure-girth profile of the same stockings as in fig 2. taken of the pressures exerted on a single limb at ankle, calf, and thigh by five different stockings. These stockings also had their pressuregirth profile determined by a different person using the new method. The pressure measurements obtained by the established method were plotted against those obtained by the new method.

Effect of ankle-calf disproportion-A potential defect of the new method is that the pressure under the stocking at any time is the same at all points and very unlike the real-life effect of a narrow ankle with a wide calf, which would result in a loosening of the weave around the ankle with a resultant loss in longitudinal stretch. To determine the potential error of this effect a narrow ankle was simulated by bandaging the latex tube with non-stretch cloth. This prevented the segment bandaged from expanding to a girth greater than $18 \mathrm{~cm}$-that is, the equivalent of a narrow ankle. The pressure-girth profile was then obtained for the calf. The non-stretch cloth was then removed and the measurements were repeated up to pressures that would produce an ankle circumference of $40 \mathrm{~cm}$. Thus the two pressure-girth profiles for the calf could be compared.

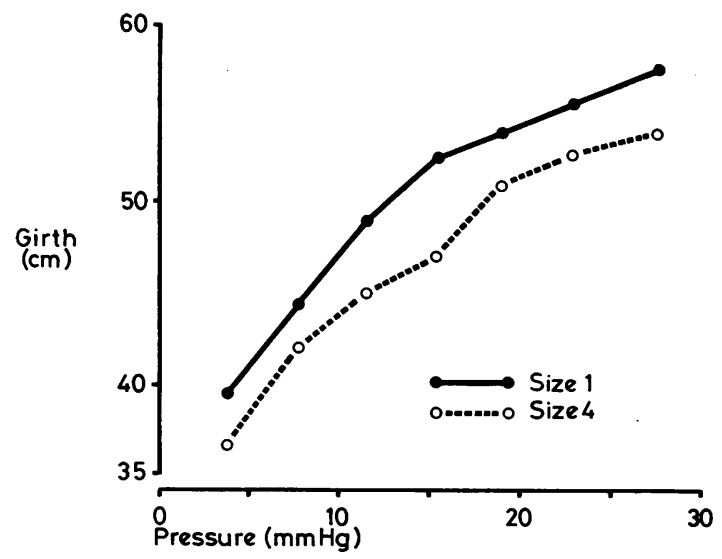

FIG 4-Thigh pressure-girth profile of the same stockings as in figs 2 and 3.

\section{Results}

The table shows the pressure-girth profile from one stocking. Figs 2 to 4 show the pressure-girth profiles for ankle, calf, and thigh for sizes 1 and 4, the smallest and largest of one brand of stockings. The table shows at a glance whether the compression exerted by the stocking is suitably graduated for any limb of known girth measurements.

Fig 5 shows the correlation between the pressures predicted for a limb from the pressure-girth profiles of five stockings with those measured directly with the polyvinyl water-filled $\mathrm{bag}^{7}$ on the same limb

The effect of the non-stretch cloth, applied at the ankle, was to increase the calf pressure-girth profile by $1 \mathrm{~mm} \mathrm{Hg}$, which could be ignored for practical purposes.

Pressure-girth profiles for one stocking, showing pressures exerted on ankles, calves, and thighs of different sizes

\begin{tabular}{|c|c|c|c|}
\hline $\begin{array}{l}\text { Pressure } \\
\text { exerted } \\
(\mathrm{mm} \mathrm{Hg})\end{array}$ & $\begin{array}{l}\text { Ankle } \\
\text { circumference } \\
\text { (cm) }\end{array}$ & 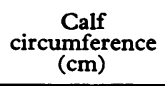 & $\begin{array}{l}\text { Thigh } \\
\text { circumference } \\
\text { (cm) }\end{array}$ \\
\hline $\begin{array}{r}3.7 \\
7.5 \\
11.2 \\
15.0 \\
18.7 \\
22.4 \\
26.2\end{array}$ & $\begin{array}{l}18.4 \\
19.0 \\
19.4 \\
21 \cdot 1 \\
22.8 \\
24.4 \\
27.1\end{array}$ & $\begin{array}{l}18 \cdot 5 \\
20.8 \\
22.4 \\
26.0 \\
29 \cdot 0 \\
32 \cdot 2 \\
35.5\end{array}$ & $\begin{array}{l}36 \cdot 2 \\
41 \cdot 9 \\
44.5 \\
47 \cdot 0 \\
50 \cdot 8 \\
52 \cdot 4 \\
53 \cdot 6\end{array}$ \\
\hline
\end{tabular}

\section{Discussion}

The new method of determining the pressure exerted by a stocking overcomes certain defects such as the destruction of the stocking and the need for individual testing on every limb that are inherent in other methods. ${ }^{6-8}$ Once the pressure-girth profile for a particular stocking is determined it can be used to predict what the pressure exerted on the ankle, calf, and thigh 


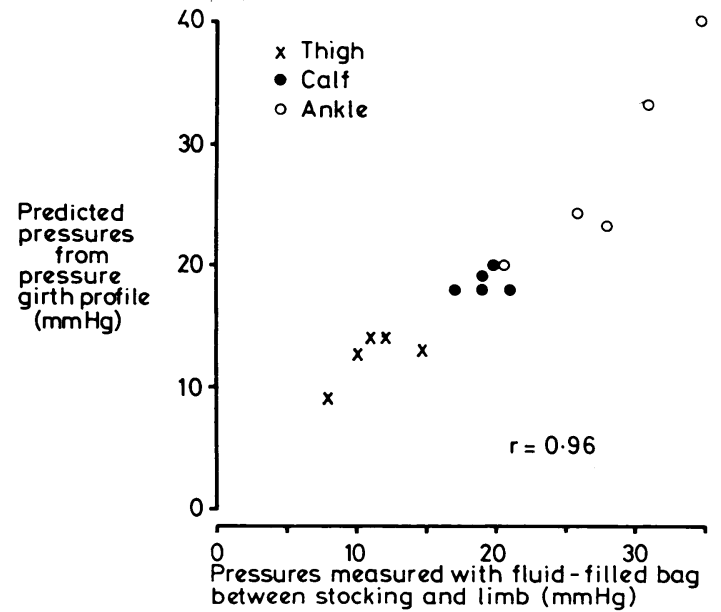

FIG 5-Correlation between predicted pressures from pressure-girth profile and pressures measured with fluidfilled bag between stockings and limb. Results are from five stockings of different size applied on the same limb.

will be for any limb. Only three simple measurements need be made of these sites using a tape measure. We have also shown the accuracy of the prediction

Possible applications for the method include quality control. During manufacture, for example, the pressure-girth profiles of batches of stockings may be measured to ensure the correct compression, and the method's use for a hysteresis test will indicate the quality of rubber used in knitting. Retesting stocking compression at intervals during routine use will show how they withstand washing and wearing and allow inferior brands to be identified. The pressure gauge may also be calibrated to give a direct reading on to a stocking-making machine, so that exact specifications of stockings can be made by the pressure readings from a standard stocking.

The most promising clinical application, however, will be to determine whether the pressure exerted by a stocking when applied on a particular limb will be graduated-that is, higher in the ankle than in the calf and thigh. The beneficial effect of stockings that produce a graduated compression on the leg has been already shown, ${ }^{2-5}$ and use of the new method will ensure that patients are fitted with such stockings (see accompanying paper).

\section{References}

${ }^{1}$ Heywood JJ. Notes on elastic hosiery. Retail Chemist 1972 Mar 30.

${ }^{2}$ Holford CP. Graded compression for preventing deep venous thrombosis. Br Med F 1976;ii:969-70.

${ }^{3}$ Sigel B, Edelstein AL, Felix WR, Memhardt CR. Compression of the deep venous system of the lower leg during inactive recumbency. Arch Surg 1973;106:38-43.

4 Sommerville JJ, Byrne PH, Fegan WG. Evaluation of elastic stockings in venous insufficiency. Br F Surg 1973;60:908.

5 Sigel B, Edelstein AL, Savitch L, Hasty JH, Felix WR. Type of compression for reducing venous stasis. A study of lower extremities during inactive recumbency. Arch Surg 1975;110:171-5.

- Sigg K. Die Kompression mit verbänden und gummistrümpfen zur prophylaxe und therapie venöser beinleiden. Forschritte der Medizin 1963;81:601.

7 Fentem PH, Goddard M, Gooden BA. Support for varicose veins. Br Med F 1976; : 254-6.

${ }^{8}$ Makin GS, Mayes FB, Holroyd AM. Studies on the effect of "tubigrip" on flow in the deep veins of the calf. Br F Surg 1969;56:369-72.

\title{
Value of graduated compression stockings in deep venous insufficiency
}

\author{
J HORNER, J FERNANDES É FERNANDES, A N NICOLAIDES
}

\section{Summary and conclusions}

The effect of elastic stockings on ambulatory venous pressure was investigated in $22 \mathrm{limbs}$ with deep venous insufficiency. The failure of some elastic stockings to reduce the ambulatory venous pressure in some limbs is due to the lack of graduated compression, which is caused by ankle-calf disproportion-narrow ankles and wide calves. This can be recognised by using the pressure-girth profile and corrected by specially made stockings with increased tension at the ankle. A pressure-girth profile established for each stocking enabled the exact compression exerted by the stocking along the length of each limb to be determined.

Elastic stockings exerting a graduated compression between ankle and calf induced a reduction in the ambulatory venous pressure in all but one limb. The greater

Academic Surgical Unit and Vascular Laboratory, St Mary's Hospital Medical School, London

J HORNER, FSC(SA), FRCSED, senior surgical registrar

J FERNANDES É FERNANDES, MD, research fellow and honorary senior registrar

A N NICOLAIDES, MS, FRCS, senior lecturer in cardiovascular surgery, director of clinical vascular laboratory the degree of graduated compression between ankle and calf exerted by the stocking, the greater the fall in ambulatory venous pressure. This may explain the beneficial effect of compression in limbs with venous ulceration.

\section{Introduction.}

The prescription of elastic stockings is the most common treatment for deep venous insufficiency, yet some patients refuse to wear them because the stockings fail to relieve their symptoms or make them worse. Elastic stockings that provide a graduated compression have been shown to reduce the ambulatory venous pressure and are therefore the stockings of choice. ${ }^{1}$

The circumferential pressure exerted on a limb by a stocking depends both on the limb circumference at different levels and the circumferential tension of the stockings at each level. It is thus incorrect to label a specific stocking as "graduated" until it has been individually matched to a patient's limb. The same stocking may exert graduated compression on one limb but not on another of different dimensions. This lack of graduated compression may be the cause of its failure to reduce the ambulatory venous pressure and relieve symptoms.

We therefore studied the effects of elastic stockings on the ambulatory venous pressure of patients with deep venous insufficiency. A brand of stockings commonly available in the 